\title{
ALOCAÇÃO DE FITOMASSA E CRESCIMENTO DE CLONES DE CAJUEIRO IRRIGADOS COM ÁGUAS DE DIFERENTES SALINIDADES
}

Allocation of phytomass and growth of cashier clones irrigated with water of different salinities

Asignación de fitomasa y crecimiento de clones de cajera irrigados con agua de diferentes salinidades

\section{Leandro de Pádua Souza ${ }^{1}$, Reginaldo Gomes Nobre ${ }^{2}$, Hans Raj Gheyi ${ }^{1}$, Reynaldo Teodoro} de Fatima*3, Elcimar Lopes da Silva ${ }^{4}$, Jutahy Jorge Elias ${ }^{5}$

${ }^{1}$ Unidade Acadêmica de Engenharia Agrícola, Universidade Federal de Campina Grande, Campina Grande, Brasil.

${ }^{2}$ Departamento de Ciências e Tecnologia, Universidade Federal Rural do Semi-Árido, Caraúbas, Brasil.

${ }^{3}$ Centro de Ciências Agrárias, Universidade Federal da Paraíba, Areia, Brasil.

${ }^{4}$ Centro de Ciência e Tecnologia Agroalimentar, Universidade Federal de Campina Grande, Pombal, Brasil.

${ }^{5}$ Unidade Acadêmica de Ciências Agrárias, Universidade Estadual da Paraíba, Campina Grande, Brasil.

*Correspondência: Centro de Ciências Agrárias, Universidade Federal da Paraíba, Rodovia PB 079 - Km 12 Caixa Postal 66 - CEP 58397-000 - Areia/PB. e-mail reynaldo.t16@ gmail.com.

\section{RESUMO}

A produção de porta-enxerto de cajueiro na região semiárida do nordeste brasileiro, onde as águas disponíveis para irrigação geralmente são salinas, está na dependência de clones de cajueiro adaptados as condições edafoclimáticas locais. Desse modo, objetivou-se com esta pesquisa, avaliar os efeitos da irrigação com águas de salinidades crescentes sob a alocação de fitomassa e crescimento de diferentes clones de cajueiros. O experimento foi desenvolvido em casa de vegetação do CCTA/UFCG, Campus Pombal - PB, utilizando-se o delineamento de blocos ao acaso, em esquema fatorial $5 \times 4$, cujos tratamentos consistiram em níveis de condutividades elétricas da água de irrigação - CEa $\left(0,3 ; 1,0 ; 1,7 ; 2,4\right.$ e 3,1 dS m$\left.{ }^{-1}\right)$ associados a distintos clones de cajueiro (CCP 76, Embrapa 51, Faga 11 e Crioulo), com três repetições e duas plantas por parcela. A salinidade da água de irrigação de até $1,30 \mathrm{dS} \mathrm{m}^{-1}$ proporciona perdas aceitáveis de $10 \%$ na alocação de fitomassa e crescimento dos clones de cajueiro. A taxa de assimilação liquida e alocação de fitomassa seca de raiz sofreram reduções à medida que se elevaram a salinidade da água de irrigação. O porta-enxerto de cajueiro Crioulo apresenta maior acúmulo de fitomassa seca total aos 65 dias após semeio.

Palavras-chave: Anacardium occidentale L., estresse salino, porta-enxerto.

\section{ABSTRACT}

Cashew rootstock production in the semi-arid region of northeastern Brazil, where the waters available for irrigation are generally saline, is dependent on cashew clones adapted to local edaphoclimatic conditions. Thus, the objective of this research was to evaluate the effects of irrigation with increasing salinity waters under the phytomass allocation and growth of different cashew clones. The experiment was carried out in a greenhouse of CCTA / UFCG, Campus Pombal - PB, using a randomized block design in a $5 \times 4$ factorial scheme, whose treatments consisted of different levels of electrical conductivity of irrigation water - CEa $\left(0.3,1.0,1.7,2.4\right.$ and $\left.3.1 \mathrm{dS} \mathrm{m}^{-1}\right)$ associated with different cashew clones (CCP 76, Embrapa 51, Faga 11 and Creole), with three replications and two plants. by

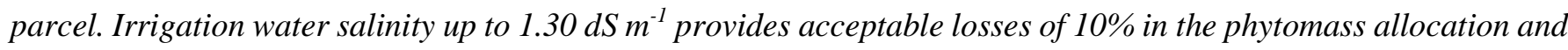
growth of cashew clones. The rate of net assimilation and allocation of dry root biomass decreased as irrigation 
water salinity increased. The Crioulo cashew rootstock has the highest total dry phytomass accumulation at 65 days after sowing.

Keywords: Anacardium occidentale L., salt stress, rootstock.

\section{RESUMEN}

La producción de portainjertos de anacardo en la región semiárida del noreste de Brasil, donde las aguas disponibles para riego son generalmente salinas, depende de los clones de anacardo adaptados a las condiciones edafoclimáticas locales. Por lo tanto, el objetivo de esta investigación fue evaluar los efectos del riego con el aumento de las aguas de salinidad bajo la asignación de fitomasa y el crecimiento de diferentes clones de anacardos. El experimento se llevó a cabo en un invernadero de CCTA / UFCG, Campus Pombal - PB, utilizando un diseño de bloques al azar en un esquema factorial $5 \times 4$, cuyos tratamientos consistieron en diferentes niveles de conductividad eléctrica del agua de riego - CEa $\left(0.3,1.0,1.7,2.4\right.$ y $\left.3.1 \mathrm{dS} \mathrm{m}^{-1}\right)$ asociado con diferentes clones de anacardo (CCP 76, Embrapa 51, Faga 11 y criollo), con tres repeticiones y dos plantas. por paquete. La salinidad del agua de riego

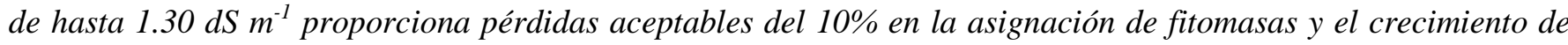
clones de anacardos. La asignación de fitomasa de hoja seca y la relación aire-hoja aumentaron mediante la adición de sal en el agua de riego. El portainjerto de anacardo Crioulo tiene la mayor acumulación total de fitomasas secas a los 65 días después de la siembra.

Descriptores: Anacardium occidentale L., estrés salino, portainjerto.

\section{INTRODUÇÃO}

O cajueiro (Anacardium occidentale L.) pertence à família Anacardiaceae, sendo uma das principais fruteiras nativas de importância socioeconómica, explorada na região Nordeste do Brasil, com uma área colhida de 585.966 hectares e uma produção de 103.848 toneladas (ALMEIDA et al., 2017).

Apesar da importância, a grande variabilidade genética do cajueiro encontrada nessa região é considerada um fator limitante da expressão do potencial produtivo da cultura. Para tentar incentivar a expansão dos pomares nessas áreas destaca-se a utilização de plantas melhoradas (cajueiro anão precoce) para substituir os pomares antigos cujas plantas foram propagadas via sementes, pois os genótipos melhorados promovem precocidade $\mathrm{e}$ produtividade superior as plantas convencionais, bem como, um porte reduzido, que facilita a colheita e tratos culturais.

No entanto, para se obter os ganhos de produção em todo o pomar se torna indispensável a utilização da propagação assexuada de forma a manter as qualidades da planta matriz usada como enxerto e porta-enxerto (SUASSUNA et al., 2016; FERREIRA et al., 2016), neste caso, o uso de porta-enxertos adaptados as condições locais tornam-se imprescidíveis à exploração sustentável da cultura.

Mesmo com tamanha participação no setor agrícola nordestino, a cajucultura vem sendo reduzida no decorrer do tempo nessa região, principalmente pela diminuição da área plantada e colhida, devido ao prolongamento do período de estiagem associados a elevada taxa de evaporação que de certa forma tem interferido nos níveis de produtividade (ALENCAR et $a l ., 2018)$. A irrigação é uma tecnologia fundamental para a exploração agrícola que vem com intuito de proporcionar condições ideais para as culturas expressarem seu potencial genético de produtividade (OLIVEIRA et al., 2010). Neste sentido, o uso de águas de qualidade inferior para irrigação das culturas tornou-se uma alternativa viável a fim de garantir a produção do cajueiro, visto que a disponibilidade dos recursos hídricos com boa qualidade é reduzida; no entanto, a utilização de águas com salinidades elevadas na produção agrícola está na dependência de técnicas que possibilitem o manejo da água e do solo, 
de forma a não comprometer as culturas e o meio ambiente (CAVALCANTE et al., 2010).

Na prática da irrigação o adequado manejo da água é de fundamental importância, pois qualquer que seja a fonte, a água de irrigação contém sais e esses podem se acumular no solo e na planta atingindo valores que podem afetar o crescimento e desenvolvimento das culturas (NAZÁRIO et al., 2010).

Desse modo, objetivou-se com esta pesquisa, avaliar os efeitos da irrigação com águas de salinidades crescentes sobre a alocação de fitomassa e crescimento de diferentes porta-enxertos de cajueiros.

\section{MATERIAIS E MÉTODOS}

A pesquisa foi conduzida no período de outubro a dezembro de 2017, em ambiente protegido (casa de vegetação), no Centro de Ciências e Tecnologia Agroalimentar da Universidade Federal de Campina Grande (CCTA/UFCG), no município de Pombal - PB, situada a 6 $47^{\prime} 3$ " S, 37049'15" W e altitude de $144 \mathrm{~m}$.

$\mathrm{O}$ delineamento experimental utilizado foi de blocos ao acaso, em esquema fatorial $5 \mathrm{x} 4$, correspondentes a cinco níveis de condutividades elétricas da água - CEa $\left(0,3 ; 1,0 ; 1,7 ; 2,4\right.$ e $\left.3,1 \mathrm{dS} \mathrm{m}^{-1}\right)$ e quatro clones de cajueiro (CCP 76, Embrapa 51, Faga 11 e Crioulo) com três repetições e duas plantas por parcela, totalizando 120 plantas. Sendo a água testemunha de CEa 0,3 $\mathrm{dS} \mathrm{m}^{-1}$ (água de abastecimento local).

Os níveis salinos testados foram baseados em estudos de Sousa et al. (2011), que observaram inibição acentuada no crescimento do cajueiro a partir do nível salino de 1,58 dS m-1.

O preparo das águas salinas foi realizado mediante a adição de sais de cloreto de sódio $(\mathrm{NaCl})$, de cálcio $\left(\mathrm{CaCl}_{2} \cdot 2 \mathrm{H}_{2} \mathrm{O}\right)$ e de magnésio $\left(\mathrm{MgCl}_{2} \cdot 6 \mathrm{H}_{2} \mathrm{O}\right)$ na água de abastecimento local (CEa de 0,3 dS m-1), na proporção equivalente de 7:2:1, relação esta predominante nas principais fontes de águas disponíveis para irrigação no Nordeste brasileiro (MEDEIROS, 1992), obedecendo-se a relação entre $\mathrm{CEa}$ e a concentração dos sais $(\mathrm{mg} \mathrm{L}-1=640 \mathrm{x} \mathrm{CEa})$ conforme Rhoades et al. (2000).

Como fator experimental foi utilizado também os clones de cajueiro onde, o clone cajueiro anão precoce Embrapa 51 foi escolhido por ser um dos mais usados como porta-enxerto por viveristas do Nordeste brasileiro e por apresentar alta taxa de germinação (SERRANO et al., 2013), o clone CCP 76 devido sua adaptabilidade a diferentes ambientes e à atratividade e qualidade do pedúnculo (VIDAL NETO et al., 2013), o clone FAGA 11 por ser recomendado para cultivo de sequeiro no semiárido Nordestino, além de apresentar características como elevada produção, castanhas grandes e pesadas (ALMEIDA, 2002) e o material Crioulo por apresentar rápido crescimento e rápida adaptação as condições ambientais (MESQUITA et al. 2010).

Todas as sementes usadas no experimento foram provenientes de uma área de exploração comercial localizada no município de Severiano Melo - RN. Já sementes do Crioulo foram provenientes de plantas vigorosas que se destacam na área devido à alta produtividade e boa qualidade das castanhas

Para a formação dos clones de cajueiro foram utilizadas sacolas de polietileno, com capacidade de $1250 \mathrm{~mL}$, perfurados na base, para livre drenagem da água. O substrato usado foi composto de Neossolo Flúvico $(95 \%)$ + esterco bovino curtido (5\%); o solo foi coletado na camada de $0-20 \mathrm{~cm}$ no Lote 14 , Setor I, do Perímetro Irrigado Várzeas de Sousa-PB. Após o preenchimento, as sacolas foram dispostas sobre uma bancada metálica (cantoneira), a uma altura de $0,80 \mathrm{~m}$ do solo para facilitar o manejo e as avaliações. 
As características físicas e químicas do substrato utilizado no experimento (Tabela 1) foram analisadas conforme metodologias propostas por Teixeira et al. (2017) no Laboratório de Irrigação e Salinidade da UFCG/Campina Grande-PB.
Foram realizados ainda tratos culturais durante o crescimento das plantas, como eliminação manual de plantas espontâneas e escarificação superficial do substrato para remoção de camadas compactadas.

Tabela 1. Características físicas e químicas do substrato utilizado no experimento.

\begin{tabular}{|c|c|c|c|c|c|c|c|}
\hline \multicolumn{8}{|c|}{ (n) } \\
\hline $\mathrm{pH}$ & $\mathrm{CE}_{\mathrm{es}}$ & $\mathrm{P}$ & K & $\mathrm{Na}$ & $\mathrm{Ca} \quad \mathrm{Mg}$ & Al & $\mathrm{H}+\mathrm{Al}$ \\
\hline $1: 2,5$ & $\mathrm{dS} \mathrm{m}^{-1}$ & $\mathrm{mg} \mathrm{dm} \mathrm{dm}^{-3}$ & & & ........ $\mathrm{cmol}_{\mathrm{c}} \mathrm{dm}^{-3} .$. & & ; \\
\hline 7,22 & 1,28 & 0,30 & 0,30 & 0,14 & $3,50 \quad 1,70$ & 0,00 & 0,00 \\
\hline \multicolumn{8}{|c|}{ 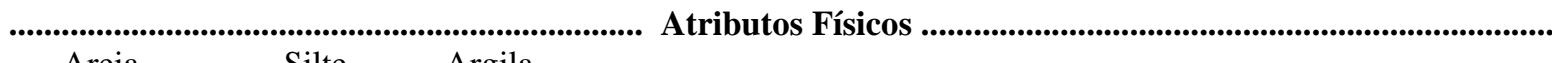 } \\
\hline Areia & Silte & Argila & DS & DP & Porosidade Total & \multicolumn{2}{|c|}{ Classe textural } \\
\hline \multicolumn{3}{|c|}{$\ldots \ldots \ldots \ldots \ldots . . . . . g ~ k g^{-1}$} & \multicolumn{2}{|c|}{$\ldots \ldots . . \mathrm{kg} \mathrm{dm}^{-3} \ldots \ldots}$. & $\%$ & \multirow{2}{*}{\multicolumn{2}{|c|}{ Franco- arenoso }} \\
\hline 767,3 & 161,6 & 71,1 & 1,44 & 2,75 & 47,63 & & \\
\hline
\end{tabular}

Antes do semeio as sementes foram selecionadas conforme tamanho e sanidade, eliminando-se as que boiassem após imersão em água. A semeadura foi realizada utilizando uma semente por sacola, cujo substrato encontrava-se na capacidade de campo com água de abastecimento (CEa de 0,3 dS m${ }^{1}$ ); a semente foi inserida na posição vertical com base voltada para cima (ponto de inserção da castanha ao pedúnculo), na profundidade de $1 \mathrm{~cm}$ de solo acima da castanha, conforme recomendações da EMBRAPACNPAT (CAVALCANTI JÚNIOR e CHAVES, 2001).

A emergência das plântulas iniciou-se aos 10 dias após o semeio (DAS), sendo a aplicação das água de irrigação com distintas salinidades iniciadas aos 25 dias após a semeio (DAS), com irrigações diárias no final da tarde de forma manual utilizando proveta graduada, sendo a lâmina aplicada estimada pelo processo de lisimetria de drenagem (utilizando 20 sacolas aleatórias que eram usadas para esse cálculo; abaixo delas tinha um coletor para determinar a drenagem), pela diferença entre o volume aplicado e o drenado da irrigação anterior (SOUZA et al., 2016). Com o propósito de reduzir o acúmulo de sais no solo foi aplicado fração de lixiviação de 0,15 em intervalo de 10 dias.
Avaliaram-se os efeitos dos tratamentos através da alocação de fitomassa seca de folha (AFSF), caule (AFSC) e raiz (AFSR); taxa de assimilação liquida (TAL), aérea foliar especifica (AFE), razão de aérea foliar (RAF), fitomassa seca de raiz (FSR) e total (FST) dos clones de cajueiro, aos 65 dias após o semeio (DAS) considerado como tempo médio necessário para as plantas apresentarem-se aptas a enxertia (SERRANO et al., 2013).

Determinaram-se a alocação de fitomassa (AF) nos diferentes órgãos (folhas, caule e raiz) conforme Benincasa (2003) equação 1:

$$
\mathrm{AF}=\left(\frac{\text { MSorgão }}{\text { MStotal }}\right) \times 100
$$

A taxa de assimilação líquida (TAL) foi obtida conforme metodologia descrita por Lucches, (1984) através da equação 2 :

$$
\mathrm{TAL}=\frac{(\mathrm{P} 2-\mathrm{P} 1)}{(\mathrm{A} 2-\mathrm{A} 1)} * \frac{(\log e \mathrm{~A} 2-\log e \mathrm{~A} 1)}{(\mathrm{T} 2-\mathrm{T} 1)}
$$

Em que: P2= Fitomassa seca total do vegetal colhido na segunda amostragem; P1 = Fitomassa seca total do vegetal coletado na primeira amostragem: $\log \mathrm{e}$ » logaritmo neperiano ( $\log \mathrm{e}=$ logaritmo decimal multiplicado por 2,30258); A2 = área foliar no tempo T2; A1 = área foliar no tempo T1; T2 e T1 = dias da segunda e primeira amostragens, respectivamente 
(número de dias decorridos entre as duas amostragens).

A área foliar especifica (AFE) e razão de área foliar (RAF) foram mensurada de acordo com Benincasa (2003), conforme a equação 3 e 4:

$$
\mathrm{AFE}=\frac{\mathrm{AF}}{\mathrm{FSF}} \quad\left(\mathrm{cm}^{2} \mathrm{~g}-{ }^{1}\right)
$$

Em que: $\mathrm{AFE}=$ área foliar específica, $\mathrm{em}^{2} \mathrm{~cm}^{2} \mathrm{~g}-1 ; \mathrm{AF}$ = área foliar, em $\mathrm{cm}^{2} ; \mathrm{FSF}=$ fitomassa seca da folha, em $g$.

$$
\mathrm{RAF}=\frac{\mathrm{AF}}{\mathrm{FSPA}}=\left(\mathrm{cm}^{2} \mathrm{~g}-{ }^{1}\right)
$$

Em que: FSPA= fitomassa seca da parte aérea (g), AF: área foliar $\left(\mathrm{cm}^{2}\right)$

Para a determinação da produção de fitomassa seca as plantas foram cortadas rente ao solo, em seguida, realizou-se a limpeza das raízes para eliminar o solo aderido e dividiu-se cada estrutura da planta em folha, caule e raiz, posteriormente, o material foi acondicionado em sacos de papel previamente identificados e levados ao laboratório e colocadas em estufa de circulação de ar à $65^{\circ} \mathrm{C}$ até obtenção do peso constante para determinação da fitomassa seca de raiz (FSR) e seca total (FST).

As distintas variáveis foram avaliadas mediante análise de variância, pelo teste $\mathrm{F}(0,01$ e 0,05 de probabilidade) e, nos casos de efeito significativo, realizou-se análise de regressão polinomial linear e quadrática para o fator salinidade da águas e, teste de média (Tukey) para comparar os diferentes clones de cajueiro, utilizando-se do software estatístico SISVAR (FERREIRA, 2011).

\section{RESULTADOS E DISCUSSÃO}

Conforme o resumo da análise de variância (Tabela 2) observa-se que houve efeito significativo $(\mathrm{p}<0,01)$ isolado dos níveis salino da água de irrigação e dos clones de cajueiro sobre alocação de fitomassa seca de folha, caule e raiz. A interação entre os fatores salinidade da água de irrigação x clones de cajueiro não foi significativa $(\mathrm{p}>0,05)$.

Tabela 2: Resumo da análise de variância para alocação de fitomassa seca de folha (AFSF), caule (AFSC) e raiz (AFSR) de diferentes clones de cajueiro irrigados com águas de salinidade crescente, aos 65

\begin{tabular}{|c|c|c|c|c|}
\hline \multirow{2}{*}{ Fonte de variação } & \multirow{2}{*}{ GL } & \multicolumn{3}{|c|}{ Quadrado Médio } \\
\hline & & AFSF & AFSC & AFSR \\
\hline salinidade (S) & 4 & $* *$ & $* *$ & $* *$ \\
\hline Reg. Linear & 1 & $* *$ & $* *$ & $* *$ \\
\hline $\begin{array}{l}\text { Reg. } \\
\text { Quadrática }\end{array}$ & 1 & ns & ns & ns \\
\hline Clones (C) & 3 & $* *$ & $* *$ & $* *$ \\
\hline Interação (SxC) & 12 & ns & ns & ns \\
\hline Bloco & 2 & ns & ns & ns \\
\hline $\mathrm{CV}(\%)$ & & 4,23 & 7,50 & 10,10 \\
\hline
\end{tabular}
dias após o semeio (DAS).

De acordo com a equação de regressão (Figura 1A) verifica-se que o aumento da condutividade elétrica da água de irrigação causou efeito linear crescente sobre a AFSF aos 65 DAS, com ganhos de $24,20 \%$ nas plantas que receberam CEa de $3,1 \mathrm{dS} \mathrm{m}^{-1}$ em relação às plantas submetidas a CEa de $0,3 \mathrm{dS} \mathrm{m}^{-1}$. Este resultado pode ser em função da menor atividade do floema na planta em condições de acúmulo de sais, provavelmente pela ocorrência de um menor aporte de potássio, reduzindo o carregamento de açúcares até os tecidos do coletor (raízes), e assim, ocorrendo uma diminuição no acúmulo de fotoassimilados em outros órgãos da planta (DREYER et al., 2017), como é observado nas figuras seguintes. Silva et al. (2013) em trabalho sobre alocação de fitomassa pela mamoneira sob estresse salino verificaram acréscimo linear na alocação de fitomassa nas folhas da mamoneira a medida que se aumentou a salinidade da água de irrigação,

Conforme resultados da análise de variância constata-se que as alocações de fitomassas secas do 
caule e raiz aos 65 DAS foram significativamente $(p<0,01)$ afetadas em função do aumento da salinidade da água de irrigação e a partir dos modelos de regressão verifica-se que os dados de AFSC e AFSR apresentaram efeito linear e decrescente indicando perdas de 4,74 e $7,84 \%$, respectivamente, por aumento unitário da condutividade elétrica da água de irrigação. Ao comparar as plantas submetidas às águas de maior nível salino $\left(3,1 \mathrm{dS} \mathrm{m}^{-1}\right)$ em relação as plantas cultivadas sob irrigação com águas de nível salino iguais a $0,3 \mathrm{dS} \mathrm{m}^{-1}$, verifica-se que houve redução de $13,28 \%$ (AFSC) e de 21,96\% (AFSR), sendo as raízes mais afetadas pelo aumento da salinidade devido estar em contado direto com os sais na solução do solo. A diminuição do potencial osmótico do meio atua de forma negativa sobre o processo fisiológico, reduzindo a absorção de água pelas raízes, inibindo a atividade meristemática e o alongamento celular e, consequentemente redução no crescimento e desenvolvimento das plantas (TRAVASSOS et al., 2011).

Figura 1: Alocação de fitomassa seca da folha (AFSF), caule (AFSC) e raiz (AFSR) em função dos distintos níveis de salinidade de água - CEa (A) e de diferentes clones de cajueiro (B), aos 65 dias após semeio - DAS
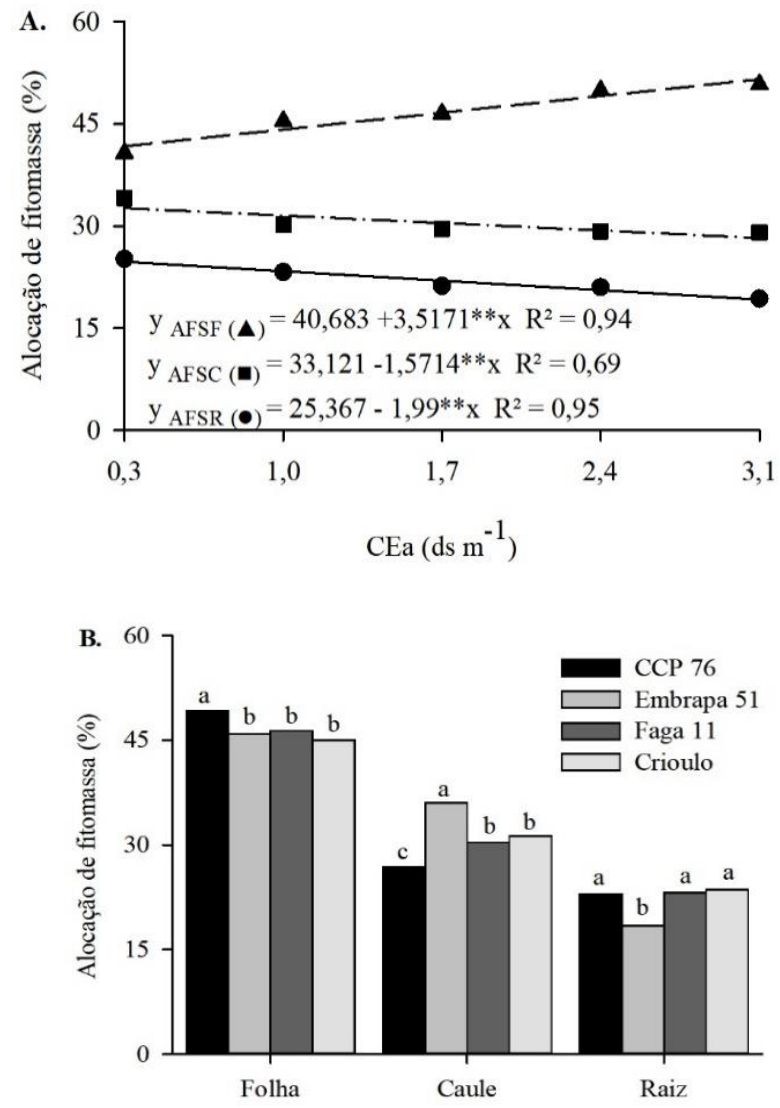

A redução na alocação de fitomassa pode estar relacionada tanto com o componente osmótico como ao iônico, ambas indissociáveis no estresse salino podendo provocar o fechamento dos estômatos, reduz a assimilação do $\mathrm{CO}_{2}$ e a taxa fotossintética afetando diretamente a produção de fitomassa (SILVA et al., 2013). Conforme Aragão et al. (2009), decréscimos na alocação de fitomassa são ocasionados pela diminuição da fotossíntese, bem como do redirecionamento da energia que seria utilizada para o crescimento, para outras atividades metabólicas relacionadas com a adaptação a salinidade, como por exemplo, a manutenção da estabilidade das membranas, produção de solutos orgânicos e controle no transporte e distribuição dos íons (ARAÚJO et al., 2017).

Para a alocação de fitomassa seca de folha (Figura 1B), as plantas de cajueiro CCP 76 mostraram superioridade em relação aos demais clones, 
apresentando valores superiores de 2,91; 3,33 e 4,24\% quando comparado aos porta-enxertos Faga 11, Embrapa 51 e o Crioulo, respectivamente. Situação essa interessante, pois neste caso, ocorre um maior investimento da planta para o desenvolvimento dos órgãos de assimilação $\mathrm{CO}_{2}$, o que pode elevar a taxa fotossintética destas plantas de cajueiro.

Em relação a Alocação de fitomassa seca do caule não foi observada diferença significativa entre os clones Crioulo e Faga 11 (Figura 1 B); já o clone Embrapa 51 proporcionou maior valor de AFSC, sendo $25,54 \%$ superior quando comparado com as plantas de CCP 76. Essa maior sensibilidade do clone de cajueiro CCP 76 em acumulação de fitomassa seca do caule pode ser uma tentativa de ajustamento às condições adversas do estresse (salino e/ou hídrico), incluindo modificações no balanço iônico, potencial hídrico, nutrição mineral, fechamento estomático, eficiência fotossintética e alocação de carbono (PINHEIRO et al., 2018). Esta redução da alocação fitomassa seca da raiz foi influenciada pelo aumento da CEa pode ser comprovada pela relação fitomassa seca da raiz/FSPA, pois as plantas irrigadas com água de $\mathrm{CE}$ de 3,1 dS m $\mathrm{m}^{-1}$ apresentaram menor acúmulo de FSR do que a FSPA. O excesso de sais na zona radicular tem, em geral, um efeito deletério no crescimento das plantas, que se manifesta por uma redução na taxa de transpiração e de crescimento. Provavelmente o excesso de sais reduziu o desenvolvimento da planta, devido ao aumento de energia que precisa ser desprendida para absorver água do solo (MEDEIROS et al., 2007).

Conforme pode ser constatado as plantas de cajueiro Crioulo apesar de não diferirem dos clones Faga 11 e CCP 76, apresentou maior alocação de fitomassa seca de raiz, já os menores resultados são observados para o clone de cajueiro Embrapa 51 $(18,43 \%)$. Fato esse que mostra um menor desprendimento de energia para o desenvolvimento do sistema radicular, o que resulta em uma redução na absorção de nutrientes, por diminuir a área de interceptação de nutrientes pela raiz (JIN et al., 2017).

Houve efeito significativo $(\mathrm{p}<0,01)$ da interação entre os fatores (salinidade da água de irrigação e de diferentes clones de cajueiro) sobre a fitomassa seca de raiz (FSR) (Tabela 3). Para as variáveis taxa de assimilação liquida, razão de aérea foliar (RAF) e fitomassa seca total (FST) aos 65 DAS; nota-se efeito de forma isolada da salinidade da água de irrigação e de diferentes clones de cajueiro e para área foliar especifica houve efeitos significativo $(\mathrm{p}<0,01)$ apenas para diferentes clones.

Tabela 3: Resumo da análise de variância para taxa de assimilação liquida (TAL), aérea foliar especifica (AFE), razão de aérea foliar (RAF), fitomassa seca de raiz (FSR) e seca total (FST) de diferentes clones de cajueiro irrigados com águas de salinidade crescentes, aos 65 dias após o semeio (DAS).

\begin{tabular}{|c|c|c|c|c|c|c|}
\hline \multirow[b]{2}{*}{$\begin{array}{l}\text { Fonte de } \\
\text { variação }\end{array}$} & \multirow[b]{2}{*}{ GL } & \multicolumn{5}{|c|}{ Quadrado Médio } \\
\hline & & $\begin{array}{c}\text { TAL } \\
\text { (g.dm- } \\
{ }^{2} \text { dia }^{-} \\
1)\end{array}$ & $\begin{array}{c}\mathrm{AFE} \\
\left(\mathrm{cm}^{2}\right. \\
\left.\mathrm{g}^{-1}\right)\end{array}$ & $\begin{array}{c}\mathbf{R A F} \\
\left(\mathbf{c m}^{2}\right. \\
\left.\mathbf{g}^{-1}\right)\end{array}$ & $\begin{array}{c}\text { FSR } \\
(\mathbf{g})\end{array}$ & $\begin{array}{c}\text { FST } \\
(\mathrm{g})\end{array}$ \\
\hline $\begin{array}{l}\text { Níveis } \\
\text { salinos (NS) }\end{array}$ & 4 & $* *$ & ns & $* *$ & $* *$ & $* *$ \\
\hline $\begin{array}{l}\text { Reg. } \\
\text { Linear }\end{array}$ & 1 & $* *$ & ns & $* *$ & $* *$ & $* *$ \\
\hline $\begin{array}{l}\text { Reg. } \\
\text { Quadrática }\end{array}$ & 1 & Ns & ns & ns & ns & $\mathrm{ns}$ \\
\hline $\begin{array}{l}\text { Clones de } \\
\text { cajueiro (C) }\end{array}$ & 3 & $* *$ & $* *$ & $* *$ & $* *$ & $* *$ \\
\hline $\begin{array}{l}\text { Interação } \\
\text { (NS x C) }\end{array}$ & 12 & Ns & ns & ns & $* *$ & ns \\
\hline Bloco & 2 & Ns & ns & ns & ns & ns \\
\hline CV (\%) & & 22,59 & 13,27 & 12,84 & 12,86 & 6,68 \\
\hline
\end{tabular}

Verifica-se (Figura 2A) que com a aplicação dos níveis salinos sobre a taxa de assimilação liquida as plantas tiveram decréscimos de 21,29\% por aumento unitário da CEa, ou seja, quando as plantas foram irrigadas com a CEa de $3,1 \mathrm{dS} \mathrm{m}^{-1}$ a TAL 
decresceu de 0,48 $\mathrm{g} \mathrm{dm}^{-2} \mathrm{dia}^{-1} \quad(59,62 \%)$, em comparação aos que estavam sob água de abastecimento $\left(0,3 \mathrm{dS} \mathrm{m}^{-1}\right)$ aos 65 DAS. Bezerra et al. (2016), testando níveis de salinidade da água de irrigação $\left(0,5\right.$ a $\left.5,5 \mathrm{dS} \mathrm{m}^{-1}\right)$, em porta-enxertos de cajueiro, não verificaram efeito significativo da $\mathrm{CEa}$ sobre TAL 40 DAS.

Figura 2: Taxa de assimilação liquida - TAL em função dos distintos níveis de salinidade de - CEa (A) e de diferentes clones de cajueiro (B), aos 65 dias após semeio - DAS.
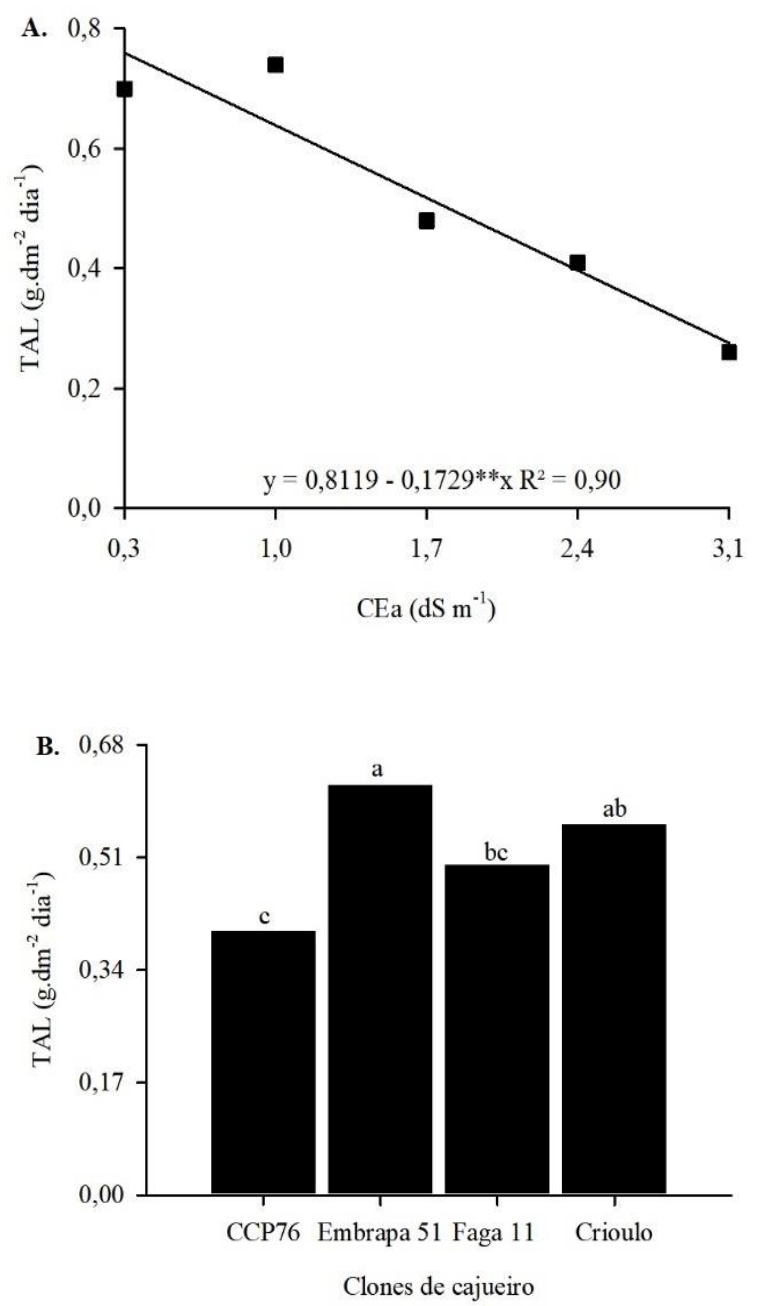

O melhor resultado para a variável taxa de assimilação liquida entre os clones de cajueiro avaliados (Figura 2B) se deu para o clone Embrapa 51, apresentando um valor $0,12 \mathrm{~g} . \mathrm{dm}^{-2} \mathrm{dia}^{-1}$ superior ao clone Faga 11 e $0,22 \mathrm{~g} \cdot \mathrm{dm}^{-2} \mathrm{dia}^{-1}$ ao CCP 76, entretanto não apresentou diferença significativa entre o Embrapa 51 e o Crioulo. Situação essa que mostra um melhor aproveitamento da área foliar fotossinteticamente ativa da planta, reduzindo gastos de energia com a expansão foliar, a qual é convertida para a atividade bioquímica da planta, melhorando a absorção de nutrientes (TAIZ et al., 2017).

A área foliar especifica foi maior também para o clone Embrapa 51, porém não apresentou diferença significativa quando comparado com o Crioulo (Figura 3). Verifica-se ainda, que o clone Embrapa 51 apresenta valores superiores em $13,71 \%$ para o CCP 76 e de 16,13\% para o Faga 11.

Figura 3: Área foliar especifica AFE em função de diferentes porta-enxerto de cajueiro, aos 65 dias após semeio - DAS.

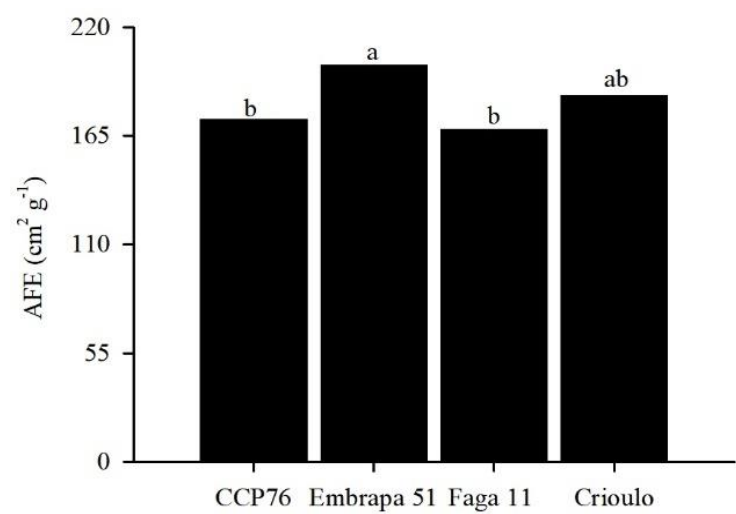

Clones de cajueiro

O incremento na salinidade da água de irrigação causou efeito linear crescente de $13,04 \%$ por aumento unitário na CEa sobre a RAF aos 65 DAS (Figura 4A). As plantas irrigadas com água de CEa de $3,1 \mathrm{dS} \mathrm{m}^{-1}$ apresentaram ganhos na RAF de $25,29 \mathrm{~cm}^{2}$ $\mathrm{g}^{-1}(36,51 \%)$ em relação as plantas irrigadas com água de abastecimento local $\left(0,3 \mathrm{dS} \mathrm{m}^{-1}\right)$ dando uma ideia de área foliar útil disponível para realizar fotossíntese em condições de estresse salino. Carneiro et. al. (2004), verificaram aumento da razão de área foliar com o incremento da salinidade em porta-enxertos de cajueiro anão precoce, onde esses mesmos autores 
atribuem tal consequência ao incremento da salinidade afetando mais severamente a produção de massa seca total. A RAF é um indicador da dimensão relativa da assimilação do aparato fotossintético, que, de acordo com este conceito, uma proporção maior do produto fotoassimilado foi utilizada na formação do aparelho fotossintético com o aumento da salinidade, corroborando com os resultados obtidos neste trabalho.

Figura 4: Razão de aérea foliar - RAF em função dos distintos níveis de salinidade de água - CEa (A) e de diferentes clones de cajueiro (B), aos 65 dias após semeio - DAS.
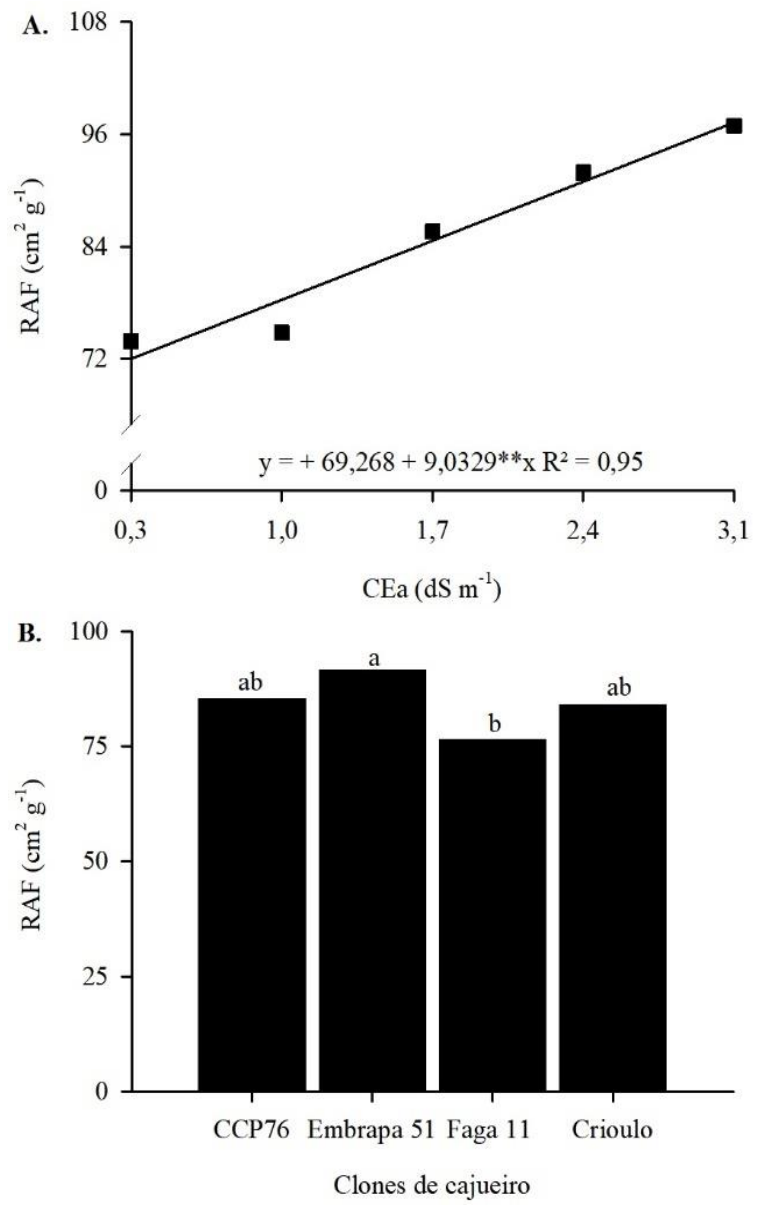

Nota-se para os diferentes clones (Figura 4B) que não houve diferença significativa para RAF entre os clones Embrapa 51, CCP 76 e o Crioulo. Entretanto observa-se uma superioridade entre o Embrapa 51 e o Faga 11 de 16,50\%, aos 65 DAS. Resultados estes que demonstram uma maior eficiência do fotossistema do clone de cajueiro Faga 11, por necessitar de uma menor área foliar para a ocorrência da fixação de carbono, provavelmente por apresentar teores mais elevados de clorofila a, que resulta em uma maior atividade da fase fotoquímica da fotossíntese e assim intensifica a atividade fotossintética e a assimilação de $\mathrm{CO}_{2}$ pela planta (OLIOSI et al., 2017).

Observa-se (Figura 5) conforme equações de regressão, que os diferentes clones de cajueiro CCP 76, Embrapa 51, Crioulo e Faga 11 sofreram reduções lineares na produção de fitomassa seca de raiz com o aumento da condutividade da água de irrigação, onde as plantas que receberam a maior CEa $\left(3,1 \mathrm{dS} \mathrm{m}^{-1}\right)$ sofreram decréscimos de 0,$72 ; 1,19 ; 1,08$ e $0,41 \mathrm{~g}$ por planta nos materiais genéticos de cajueiro CCP 76, Embrapa 51, Crioulo e Faga 11 quando comparadas com as plantas que receberam a menor salinidade $(0,3$ $\mathrm{dS} \mathrm{m}^{-1}$ ), nota-se entretanto uma maior redução na produção de FSR do clone Embrapa 51 pode ser em função de maior sensibilidade deste material ao acúmulo de sais próximo as raiz refletindo o custo metabólico de energia maior, reduzindo o acúmulo de biomassa (TRAVASSOS et al., 2011). Entretanto o clone de cajueiro Faga 11 pode ser irrigado com água de CEa de até $1,15 \mathrm{dS} \mathrm{m}^{-1}$ apresentando reduções aceitáveis de $10 \%$ sendo mais sensível o clone de cajueiro Embrapa $51\left(0,51 \mathrm{dS} \mathrm{m}^{-1}\right)$.

Figura 5: Fitomassa seca de raiz - FSR em função da interação entre distintos níveis de salinidade de água de CEa e diferentes clones de cajueiro, aos 65 dias após semeio - DAS. 


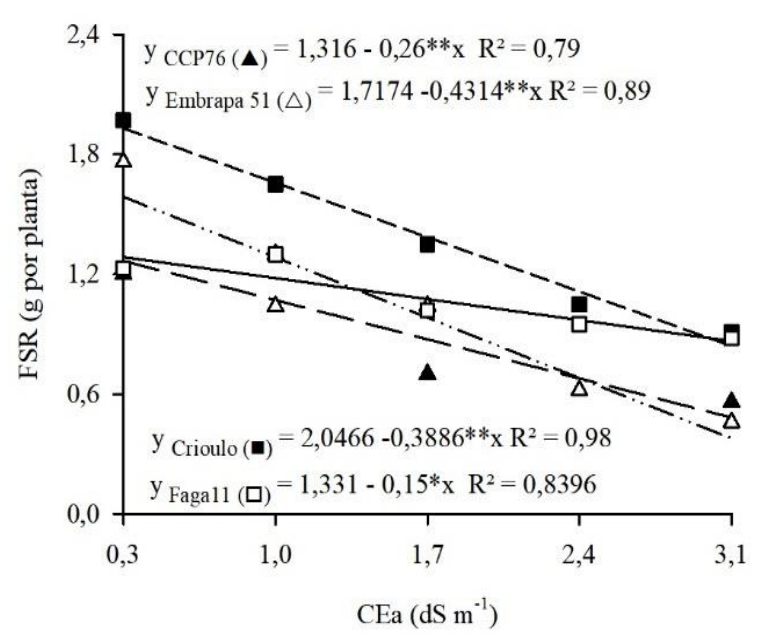

A elevação dos sais na água de irrigação afetou negativamente o acúmulo FST e através da equação de regressão (Figura 6A), nota-se efeito linear e decrescente, proporcionando uma diminuição na FST de 13,90\% por aumento unitário da CEa, portanto, as plantas irrigadas com CEa de 3,1 $\mathrm{dS} \mathrm{m}^{-1}$ tiveram decréscimo de 2,49 g (38,93\%) quando comparadas com as irrigadas com o menor nível salino $(0,3 \mathrm{dS}$ m$\left.{ }^{1}\right)$. Sendo observado uma redução de $10 \%$ na FST quando se irrigou com CEa de $0,93 \mathrm{dS} \mathrm{m}^{-1}$. Souza et al. (2016) observaram redução na acumulação de fitomassa de porta-enxerto de goiabeira "Crioula" sob estresse salino, esta diminuição pode estar associada a abscisão foliar e redução da área foliar, em função da senescência precoce causada pela ação tóxica do excesso de sais na água de irrigação, fato comprovado no presente trabalho.

Figura 6: Fitomassa seca de Total - FST em função dos distintos níveis de salinidade de água - CEa (A) e de diferentes clones de cajueiro (B), aos 65 dias após semeio - DAS.
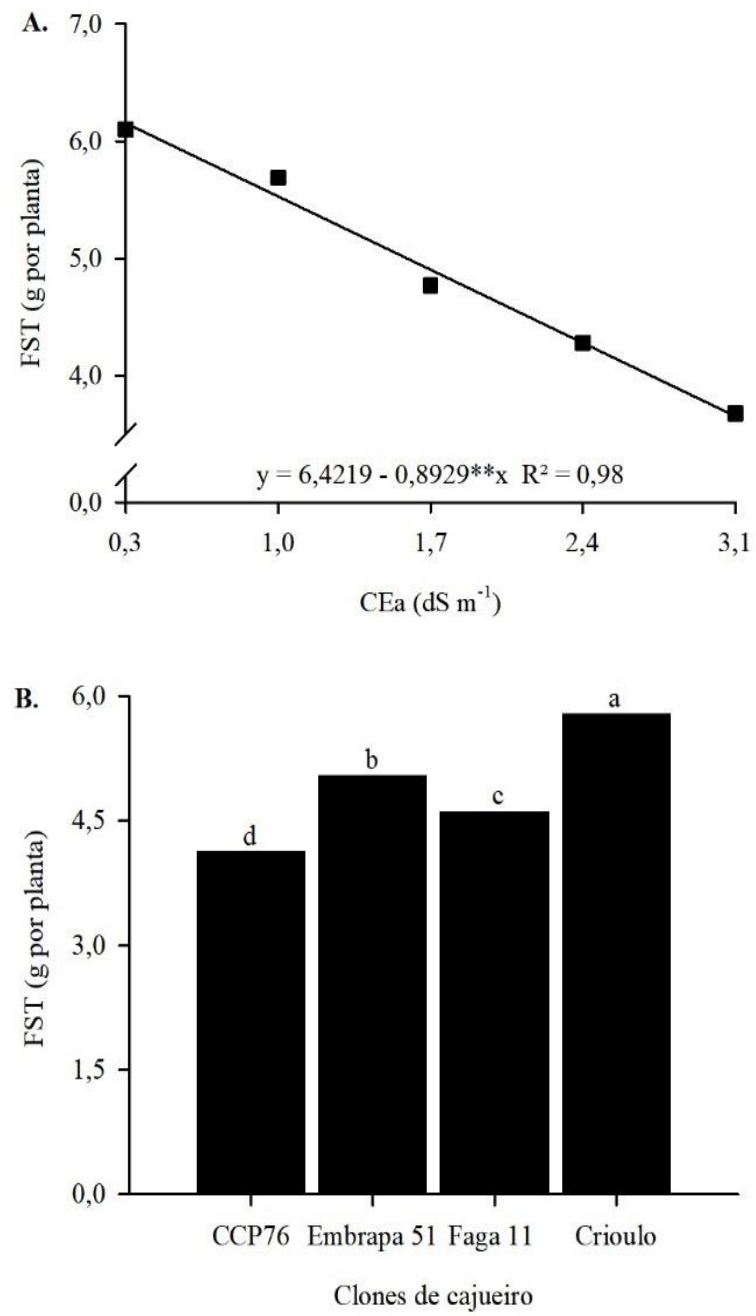

A produção de fitomassa seca total do portaenxerto Crioulo (Figura 6B), foi superior quando comparado com os demais clones de cajueiro. Observando-se que o porta-enxerto Crioulo apresentou superioridade em FST em relação as plantas de cajueiro Embrapa 51 (0,74 g por planta), do Faga 11 (1,18 g por planta) e do CCP 76 (1,66 g por planta). Situação essa que pode estar associada a melhor adaptação do cajueiro Crioulo as condições ambientes presentes na pesquisa, provavelmente pela elevada variabilidade genética presente nesse material, o que contribuiu para o aumento da atividade fotossintética e, consequente, fixação de carbono (SILVA et al., 2016).

\section{CONCLUSÃO}


A salinidade da água de irrigação de até 1,30 $\mathrm{dS} \mathrm{m}^{-1}$ proporciona perdas aceitáveis de $10 \%$ na alocação de fitomassa e crescimento dos clones de cajueiro.

A taxa de assimilação liquida e alocação de fitomassa seca de raiz sofreram reduções à medida que se elevaram a salinidade da água de irrigação.

O porta-enxerto de cajueiro Crioulo apresenta maior acúmulo de fitomassa seca total aos 65 dias após semeio.

\section{AGRADECIMENTO}

Ao centro de Ciência e Tecnologia Agroalimentar da Universidade Federal de Campina Grande pela disponibilidade da infraestrutura necessária a realização da pesquisa, ao CNPQ e a CAPES pela concessão da bolsa de estudos.

Todos os autores declararam não haver qualquer potencial conflito de interesses referente a este artigo.

\section{REFERÊNCIAS}

ALENCAR, N.S.; GONÇALVES, J. F.; OLIVEIRA, E. A. F de.; LUCENA, T. C de.; SOUSA, R. M de. Produção da castanha de caju nas microrregiões do Ceará no período de 1993 a 2016. Revista Eletrônica Competências Digitais para Agricultura Familiar, v. 4, n. 1, p. 103-116, 2018.

ALMEIDA, F. A. G. Sucesso do cajueiro anão: clones de castanhas grandes e pesadas geneticamente desenvolvido para a indústria. In: $9^{\circ}$ Semana Internacional da Fruticultura, 9, Floricultura eAgroindústria, 9, 2002, Fortaleza. Anais..., Fortaleza: Instituto de Desenvolvimento da Fruticultura e Agroindústria, 2002.

ALMEIDA, L.H.F.; CORDEIRO, S.A.; PEREIRA, R.S.; COUTO, L.C.; LACERDA, K.W. S. Viabilidade econômica da produção de caju (Anacardium occidentale L.). Nativa, v. 5, n. 1 p. 09-15, 2017.

ARAÚJO, R.P.S.; SILVA, E.C.A.; SANTOS, C.A.; PACHECO, C.M.; NOGUEIRA, R.J. M.C. Influência da salinidade no crescimento inicial de mudas de Jatropha curcas L. Revista Agrotecnologia, v.8, n.1, p.55-62, 2017.
BENINCASA, M. M. P. Análise de crescimento de plantas, noções básicas. 2 ed. Jaboticabal: FUNEP, 2003. $41 \mathrm{p}$.

BEZERRA, I.L.; NOBRE, R.G.; GURGEL, M.T.; GHEYI, H.R.; FERNANDES, P.D. Indices fisiológicos e de crescimento de porta-enxertos de cajueiro anão-precoce sob estresse salino. Revista Espacios, v 38, n. 2. p. 4. 2017.

CARNEIRO, P.T.; FERNANDES, P.D.; GHEYI, H.R.; SOARES, F.A.L.; VIANA, S.B.A. Salt tolerance of precocious-dwarf cashew rootstocks physiological and growth indexes. Scientia Agricola, v. 61, n. 1, p. 9-16, 2004.

CAVALCANTE, L.F.; CORDEIRO, J.C.; NASCIMENTO, J.A.M.; CAVALCANTE I.H.L.; DIAS, T. J. Fontes e níveis da salinidade da água na formação de mudas de mamoeiro cv. Sunrise solo. Semina: Ciências Agrárias, v.31, n. 1, p.1281- 1290, 2010 .

CAVALCANTI JÚNIOR, A. T., CHAVES, J. C. M. Produção de mudas de cajueiro. Embrapa Agroindústria Tropical, v.43, n.3, p. 42, 2001.

DREYER, I.; GOMEZ-PORRAS, J.L.; RIEDELSBERGER, J. The potassium battery: a mobile energy source for transport processes in plant vascular tissues. New Phytologist, v. 216, n. 4, p. 1049-1053, 2017.

FERREIRA， L.G.; NEGRINI JUNIOR, E.; VALENTE, J.P.; TÁVORA, C.; FERREIRA, C. B. Avaliação de métodos de exertia para mangueira e cajueiro na baixada Cuiabana. Ensaios e Ciência: Ciência Biológicas, Agrárias e da Saúde, v. 20, n. 3 , p. 128-132, 2016.

JIN, K.; WHITE, P.J.; WHALLEY, W.R., SHEN, J.; SHI, L. Shaping an optimal soil by root-soil interaction. Trends in Plant Science, v. 22, n. 10, p. 823-829, 2017.

LUCCHESI, A. A. Utilização prática da análise de crescimento vegetal. Anais da E. S. A. "Luiz de Queiroz”. v. 41, n. s/n, p. 189-190, 1984.

MEDEIROS, J.F. Qualidade de água de irrigação e evolução da salinidade nas propriedades assistidas pelo GAT nos Estados de RN, PB e CE. Dissertação Mestrado. Universidade Federal da Paraíba- UFPB; 1992.

MEDEIROS, J.F.; SILVA, M.C.C.; SARMENTO, D.H.A.; BARROS, A.D. Crescimento do meloeiro cultivado sob diferentes níveis de salinidade, com e 
sem cobertura do solo. Revista Brasileira de Engenharia Agrícola e Ambiental, v.11, n.3, p.248255, 2007.

MESQUITA, V. P., SILVA FILHO, C. J. S., MOTA, D. L. F., SEOLATTO, A. A. Avaliação da capacidade de adsorção de chumbo em cascas de frutas comuns no cerrado brasileiro. Encontro Brasileiro de Engenharia Química, 18. 2010.

NAZÁRIO, A.A.; GARCIA, G.O.; GONÇALVES, I.Z.; MADALÃO, J.C.; ARAUJO, G. L. Crescimento do cafeeiro conilon irrigado com água salina. Engenharia Ambiental, v. 7, n. 3, p. 178 -195, 2010.

OLIOSI, G.; RODRIGUES, J.D.O.; FALQUETO, A.R.; PIRES, F.R.; MONTE, J.A.; PARTELLI, F.L. Fluorescência transiente da clorofila a e crescimento vegetativo em cafeeiro Conilon sob diferentes fontes nitrogenadas. Coffee Science, v. 12, n. 2, p. 248 - 259, 2017.

OLIVEIRA, A.F.; OLIVEIRA, F.R.A.; CAMPOS, M.S.; OLIVEIRA, M.K.T.; MEDEIROS, J.F.; SILVA, O. M. P. da. Interação entre salinidade e fontes de nitrogênio no desenvolvimento inicial da cultura do girassol. Revista Brasileira Ciência Agrária, v.5, n.4, p.479-484, 2010.

PINHEIRO, F.W.A.; NOBRE, R.G.; SOUZA, L.P.; ALMEIDA, L.L.S.; MELO, E.N.; BONIFÁCIO, B.F. Crescimento de mudas de aceroleira "CMI 102" irrigadas com águas salinizadas e adubação nitrogenada. Revista Brasileira de Agricultura Irrigada v.12, n.3, p. 2632 - 2643, 2018.

RHOADES, J. D., KANDIAH, A., MASHALI, A. M. Uso de águas salinas para produção agrícola. Campina Grande: UFPB, 2000, 117 p. Estudos da FAO, Irrigação e Drenagem, 48, revisado.

SERRANO, L.A.L.; MELO, D.S.; TANIGUCHI, C. A.K.; VIDAL NETO, F.C.; CAVALCANTE JÚNIOR, L. F. Porta enxertos para a produção de mudas de cajueiro. Pesquisa Agropecuária Brasileira, Brasília, v.48, n.9, p.1237-1245, 2013.

SILVA, L.P.; RAMOS, M.L.G.; CRUZ, A.F.; RIDEIRO JUNIOR, W.Q.; RODRIGUES, G.,
OLIVEIRA, S.A.; CALBO, M.E. Fotossíntese em diferentes genótipos de feijoeiro. Revista Agroecossistemas, v. 8, n. 1, p. 20-40, 2016.

SILVA， S.S.; SOARES, L.A.A.; LIMA， G.S.; NOBRE, R.G.; GHEYI. H.R. Alocação de fitomassa pela mamoneira sob estresse salino e doses de nitrogênio. Revista Verde de Agroecologia e Desenvolvimento Sustentável, v. 8, n. 3, p. 182-187, 2013.

SOUSA, A.B.; BEZERRA, M.A.; FARIAS, F.C. Germinação e desenvolvimento inicial de clones de cajueiro comum sob irrigação com água salina. Revista Brasileira de Engenharia Agrícola e Ambiental, v.15, n.4, p.390 394, 2011.

SOUZA, L.P.; NOBRE, R.G.; SILVA, E.M.; LIMA, G.L.; PINHEIRO, F.W.A.; ALMEIDA, L.L.S. Formation of 'Crioula' guava rootstockunder saline water irrigation and nitrogen doses. Revista Brasileira Engenharia Agrícola Ambiental, v. 20, n. 8, p. 739 - 745, 2016.

SUASSUNA, C.F.; FERREIRA, N.M.; SÁ, F.V.S.; BERTINO, A.M.P.; MESQUITA, E.F.; PAIVA, E.P.; BERTINO, A.M.P. Substratos e ambientes para produção de mudas de cajueiro anão precoce. Agrarian, v. 9, n. 33, p. 197-209, 2016.

TAIZ, L. ZEIGER, E. Fisiologia e desenvolvimento vegetal. 6.ed. Porto Alegre: Artmed, 2017. 888p.

TEIXEIRA, P. C., DONAGEMMA, G. K., FONTANA, A. TEIXEIRA, W. G. Manual de métodos de análise de solos. 3.ed. Rio de Janeiro: Embrapa Solos, 2017.

TRAVASSOS, K.D.; SOARES, F.A.L.; GHEYI, H. R.; DIAS, N.S.; NOBRE, R.G. Crescimento e produção de flores de girassol irrigado com água salobra. Revista Brasileira de Agricultura Irrigada, v. $5, \mathrm{n}^{\mathrm{o}} .2, \mathrm{p} .123-133,2011$.

VIDAL NETO, F. C., BARROS, L. M., CAVALCANTI, J. J. V., MELO, D. S. Melhoramento genético e cultivares de cajueiro. Agronegócio caju: práticas e inovações. Brasília, DF: Embrapa, 481508, 2013 